\title{
A mobilidade turística na Região das Baixadas Litorâneas (RJ)
}

\author{
The tourist mobility in the Região das Baixadas Litorâneas (RJ, Brazil)
}

\section{Ulisses da Silva Fernandes}

\section{RESUMO}

O presente trabalho tem por objetivo demonstrar a ocorrência do fenômeno da mobilidade turística em uma das porções do território fluminense, a Região das Baixadas Litorâneas. Neste fragmento territorial, a atividade turística tem se manifestado como uma das maiores responsáveis pela transformação socioespacial local. O questionamento central incide sobre a existência ou não de uma interação regional marcada pela atividade turística. De modo secundário, questiona-se sobre a pertinência da adequação conceitual no trato do recorte elegido enquanto uma região turística. A operacionalização da pesquisa, para além da revisão bibliográfica pertinente, baseou-se em entrevistas de campo em munícipios da região previamente elegidos para tal: Armação dos Búzios, Arraial do Cabo e Cabo Frio. Os resultados da pesquisa apontam para uma interação turística heterogênea dentro da região analisada, sendo esta uma das razões conexas para considerar o recorte enquanto uma área turística e não exatamente uma região turística.
\end{abstract}

PALAVRAS-CHAVE: Turismo; Mobilidade Turística; Região das Baixadas Litorâneas; Estado do Rio de Janeiro.

\begin{abstract}
This paper aims to demonstrate the phenomenon of touristic mobility in one of the regions of the state of Rio de Janeiro, Região das Baixadas Litorâneas. In this territorial fragment, touristic activity has presented itself as one of the most relevant factors for local socio-spatial transformation. The central questioning lies upon the existence or nonexistence of regional interaction marked by touristic activity. Secondarily, it is questioned whether or not is the conceptual adequacy as to the selected territorial fragment as a touristic region pertinent. The operationalization of the research, beyond the pertinent bibliographical study, was based on field interviews conducted in previously chosen municipalities within the region: Armação dos Búzios, Arraial do Cabo e Cabo Frio. The research results point toward a heterogeneous touristic interaction within the analyzed region, the latter being one of the connected reasons not to consider the discriminated territory exactly as a touristic region, but rather as a touristic area.
\end{abstract}

KEYWORDS: Tourism; Touristic Mobility; Região das Baixadas Litorâneas; Estado do Rio de Janeiro. 


\section{Introdução}

O trabalho ora apresentado advém de relatório de pesquisa realizado para atender a apoio institucional a recém-doutores da FAPERJ - Fundação Carlos Chagas de Amparo à Pesquisa - RJ. Sua motivação básica, para além de vínculo com a realidade socioespacial fluminense, está na possibilidade de se manter vínculo com uma das temáticas de maior apelo social dos últimos tempos, que é a da atividade turística contemporânea.

Parte-se da tentativa de entendimento sobre a abrangência do fenômeno do turismo em uma das porções do território fluminense cuja atividade turística tem despontado como uma das de maior transformação da realidade socioespacial local: a Região das Baixadas Litorâneas. A prática turística, intensificada a partir dos anos setenta do século passado, principalmente após a construção da rodovia federal BR-101 e da chamada Ponte Rio-Niterói, gerou uma pretensa região turística de forte mobilidade, mesmo a nível internacional.

Objetiva, pois, este trabalho, demonstrar a ocorrência de uma mobilidade turística dentro da porção do território fluminense cujo senso comum reconhece como Região dos Lagos. Daí deriva o principal questionamento a ser feito, que é se de fato há uma interação regional, notabilizada pela atividade turística, capaz de estabelecer laços entre os municípios locais quanto à questão da mobilidade turística. Por outro lado, enquanto uma questão secundária, torna-se fundamental definir se há adequação conceitual adequada para tratar o recorte elegido enquanto um região turística.

A operacionalização desta pesquisa, para além da devida revisão bibliográfica, contou também a realização de pesquisa de campo, com a aplicação de duzentos questionários. Sua redação pressupõe uma análise teórico-conceitual inicial, bem como uma posterior interação com o recorte empírico, principalmente através da utilização dos dados coletados em campo.

\section{Turismo: motivações e mobilidade}

O Turismo é, decididamente, um fenômeno que passa pela esfera econômica, social, política e cultural, apresentando-se de modo significativo nas "sociedades ditas pós-industriais" (RODRIGUES, 1999, p.17). Desse modo, o Turismo vem ganhando, cada vez mais, espaço tanto nas discussões políticas e acadêmicas quanto populares. No entanto, há autores que advogam a necessidade de um estudo científico do Turismo mais apurado, como nos contam Gareth Shaw e Allan Williams, pois "embora venha crescendo o número de exceções, o estudo científico do turismo ainda é frequentemente descritivo, ateórico e caoticamente conceitualizado por ser extraído das relações sociais mais amplas" (SHAW; WILLIAMS, 2004, p.1).

Pensar o Turismo é, dentre outras coisas, debater a mobilidade que ocorre 
durante o fenômeno. É necessário, entretanto, atentar para o fato de que a mobilidade turística está interligada com várias formas de mobilidade, "tais como a migração de trabalho ou conhecimento e transferência de capital" (SHAW; WILLIAMS, 2004, p.1). A mobilidade de pessoas, no âmbito internacional, foi, efetivamente, afetada com a globalização. O fluxo turístico, em determinados espaços e lugares, é moldado pelo processo de globalização, requerendo um entendimento do turismo como um fenômeno que está estritamente ligado ao cotidiano, à constituição de comunidades e ao funcionamento do sistema social e natural, e não como um fenômeno social independente.

O nosso desafio, enquanto pesquisadores do turismo, é buscar entender como o turismo molda e é moldado pelos processos sociais. Para tanto, se faz necessário uma perspectiva de mudança, e para isso podemos nos basear no conceito de vias e fluxos, entendido como "rede de máquinas, tecnologia, organizações, textos e atores que constituem vários nós interconectados, ao longo do qual o fluxo pode ser retransmitido" (URRY, 2000, p.35).

O referido autor propõe uma paisagem do turismo que seria composta por vias e fluxos. Segundo ele, o espaço do turismo é fortemente estruturado por vias - autoestradas, rotas de voo, aeroportos - que facilitam e canalizam o movimento. Como defende o próprio John Urry, em O Olhar do Turista:

\begin{abstract}
as vias mais distorcem do que afirmam ou reforçam as fronteiras, é verdade que muitas viagens ocorrem fora destas, mas são fundamentais para entender o volume dos fluxos do turismo [...]. Essas vias são mais do que apenas rotas de transporte, estas são também compostas pelos investimentos materiais em hotéis, restaurantes e outros serviços que facilitam a viagem (URRY, 2000 apud SHAW; WILLIAMS, 2004, p.3).
\end{abstract}

O turismo de massa - que atualmente encontramos no Brasil, em cidades como Salvador (BA) em época de Carnaval e em Cabo Frio (RJ) na alta temporada do verão, quando os turistas geralmente da classe média se dirigem a essas localidades para usufruírem de um turismo sazonal e de mais baixo custo se comparado ao turismo elitista - é, particularmente, influenciado por essa estrutura constituída por vias que, destarte, vão facilitar o fluxo turístico. Não só esse tipo de turismo é constituído por vias e fluxos, mas outros também como, por exemplo, o ecoturismo e o turismo esportivo.

A importância das vias, pois, reside no fato de contribuírem para a predominância da localização relativa sobre a localização absoluta. Na dita pósmodernidade, a distância direta entre o ponto de origem e o ponto de destino perdem importância, caracterizando, lato sensu, o modo de vida do homem moderno, que, no contexto na globalização do turismo, interconecta-se com o 
mundo de modo ágil e efêmero. As vias são caracterizadas pela inércia, resultando da tecnologia, do capital investido e pelo conhecimento embutido nelas. No entanto, podem sofrer mudanças que variam de acordo com os interesses do capital. Por isso, pelo contrário, as vias estão em constante mutação, sendo (re) construídas e revistas no espaço da globalização do Turismo.

Como já se foi dito, o turismo de massa é constituído por vias e fluxos que permitem a melhor mobilidade dos turistas no espaço. No entanto, cabe indagar: a existência dessas vias e fluxos funcionaria também como motivação turística? E se funcionarem, são hermeticamente a única motivação para que uma pessoa se desloque? De fato, as vias e fluxos se encaixam na categoria de motivações turísticas, todavia não estão isoladas, pelo contrário, há muitas outras motivações que, neste artigo, serão englobadas em categorias gerais, apenas para fins didáticos.

Primeiramente, há de se clarificar o que se entende por motivação. O conceito de motivação sugere que os indivíduos constantemente visam alcançar um estado de estabilidade (GOSSENS, 1998 apud SHAW; WILLIAMS, 2004). Além disso,

tal equilíbrio é interrompido quando o individuo percebe que necessita de algo. Isso levou à criação das necessidades básicas na experiência dos turistas, tais como: novidades, satisfação sexual, estimulação, relaxamento e a auto-expressão (SHAW; WILLIAMS, 2004, p.140).

Em segundo lugar, as abordagens concernentes à motivação do turismo apontam para similaridades que emergiram de diferentes autores. Neste caso, comungamos da mesma metodologia utilizada pelos autores supracitados, que defendem que "essas diferentes abordagens podem ser categorizadas em três perspectivas; reducionista, estruturalista e funcionalista" (SHAW \& WILLIAMS, 2004, p. 140). Deve-se ficar claro, pois, que essas três perspectivas propostas pelos autores não são únicas, na tentativa de generalização de categorias de motivações turísticas, mas são aquelas que sistematizam as abordagens de tal temática de modo mais abrangente.

A perspectiva reducionista, segundo Cohen (1972 apud SHAW; WILLIANS, 2004), entende a motivação do turismo como uma tensão entre a procura de novas experiências e a exigência de algum grau de familiaridade. $O$ turista, de acordo com tal visão, teria como motivação principal a busca por novidades e pela identificação com o lugar.

A perspectiva estruturalista concentra-se em identificar uma série de variáveis motivacionais que seriam determinadas por fatores de repulsão e atração. Nos trabalhos que se baseiam nessa perspectiva, é dado mais ênfase no fator repulsão, porque este seria o condicionante para a decisão do turista de viajar. Nes- 
se sentido, observa-se "motivos mais duradouros, problemas internos ou fatores de repulsão que resultam na vontade do turista de procurar por objetos, eventos e situações" (GNOTH, 1997 apud SHAW; WILLIAMS, 2004, p.141).

Gossens (1998 apud SHAW; WILLIANS, 2004) argumenta que o conceito de emoção é o fator psicológico que conecta os fatores de atração-repulsão da motivação. Nesse sentido, "os turistas são expulsos pelas suas necessidades emocionais e atraídos pelos benefícios emocionais do local de destino" (GOSSENS, 1998, p. 302 apud SHAW; WILLIAMS, 2004, p.141). Motivação, para Gossens, tem relação com o consumo hedônico, onde o processo de motivação se daria em três estágios: o primeiro seria a fase do envolvimento do turista com o espaço, podendo levar a dois caminhos, a excitação e a consequente atração ou o estresse e a consequente repulsão; o segundo seria o momento em que, após o sentimento inicial, o turista processa as informações; e o terceiro, seria o chamado estágio hedônico, que leva ao próprio consumo.

A terceira grande abordagem das motivações turísticas compreende o funcionalismo, proposta por Fodness (1994). Este argumenta que tomamos certas atitudes devido a necessidades psicológicas importantes. Dentro da perspectiva funcionalista, essas necessidades podem criar certas tensões de natureza psicológica ou física. Tais tensões, como dizem Shaw e Williams (2004), são liberadas por ações que podem envolver sair de férias.

Diante dessas três abordagens, emergem dois problemas-chave: o primeiro seria o fato dessas abordagens não constituirem um modelo para uma teoria sólida da motivação turística, assim como defendem Pearce e Butler (1994); o segundo, está relacionado à profunda dificuldade em sistematizar as motivações do turismo. No entanto, essa complexidade que reveste a sistematização das motivações turísticas, não elimina a proeminente importância das motivações no processo decisório do turista. De fato, as motivações constituem ponto crucial quando se propõe analisar o fenômeno da mobilidade de população dentro da lógica turística.

Por outro lado, o movimento de população sobre o espaço tem se tornado cada vez mais importante na determinação de análises socioeconômicas em termos dos tipos de mobilidade que estão se configurando. Alguns autores enfocam a questão da mobilidade como parte importante de investigação em busca do entendimento da sociedade contemporânea. Nesse sentido, tem-se o exemplo do turismo enquanto forma de lazer (GUIMARÃES, 2001) que pode, por sua vez, ser inserido na categoria mobilidade, fenômeno genérico que pressupõe várias formas de transporte, deslocamentos diários entre comunidades - como aqueles relativos ao trajeto casa-trabalho e vice-versam - e outras formas de viagens, assim como suas diversas inter-relações através de várias formas de comunicação (LASH; URRY, 1994).

Diante disso, as novas condições de mobilidade apontariam para a configuração de um "pós-turismo" associado à presença difusa de signos em todos os lu- 
gares (URRY, 1996). Harvey (1996), ao situar as principais tendências do capitalismo, também destaca a importância dos signos, ao afirmar que vivemos numa dimensão da compressão do tempo/espaço, na qual se consomem mais símbolos e imagens do que propriamente coisas ao assimilarmos a publicidade e a mídia, dimensões especiais nesse cenário.

Para Hannam, Sheller e Urry (2006), novos lugares e tecnologias ao mesmo tempo que aumentam a mobilidade de algumas pessoas e lugares, também aumentam a imobilidade de outras [exemplos das pessoas que buscam cruzar fronteiras], implicando em estruturas de poder e posição de raça, gênero, classe etc. Dessa forma, tornar-se claro os efeitos da globalização sobre a mobilidade de população, uma vez que para uns praticar a mobilidade, no caso turística, consiste uma atividade comum, já para outros essa prática não faz parte de sua dimensão social.

Isto posto, parte-se para a análise de um recorte específico, o da Região das Baixadas Litorâneas, no Estado do Rio de Janeiro, como forma de verificação do até então advogado. O recorte, em si, guarda interconexões com o turismo de escala global, sendo objeto de consumo turístico de frequentadores oriundos de porções diversas do planeta, para além da própria escala local-nacional de atração turística. Por outro lado, guarda dimensões do que pode ser chamado de região turística, ou área turística, onde a mobilidade relativamente fácil e a co-proximidade de centros turísticos inside numa flutuação turística dentro dos seus limites.

As questões elencadas previamente remetem à necessidade de se compreender se esta mobilidade se dá de forma homogênea dentro de toda a região ou área turística ou se há outras motivações a determinar um uso turístico mais heterogêneo, com segregação turística, onde o fluxo seria mais ou menos intenso conforme a prévia avaliação dos centros turísticosa existentes. Para tanto, torna-se mister categorizar região ou área turística, bem como avaliar sua pretensa configuração tendo por base o recorte espacial elegido nesta pesquisa.

\section{O turismo na região das baixadas litorâneas $(\mathbf{R J})$}

Como indica o Caderno de Turismo do Estado do Rio de Janeiro, a atividade turística no território fluminense "é influenciada pela enorme diversidade de paisagens e características topográficas e climáticas, além das peculiaridades culturais existentes" (GOMES, 2010, p.50). De certo, como também preconiza o estudo, a atividade tornou-se fundamental para o desenvolvimento de algumas porções do Estado, visto ter o turismo se tornado, em alguns casos, atividade polarizadora do desenvolvimento social e econômico de alguns municípios fluminenses. De fato, pela argumentação do geógrafo Miguel Angelo Ribeiro, "o Estado do Rio de Janeiro é uma das unidades federadas que apresenta importância para a promoção do turismo brasileiro, atividade esta que merece destaque no contexto do desenvolvimento econômico de nosso Estado" (RIBEIRO, 2003, p.80). 
Neste mesmo artigo, o autor destaca a existência de condicionantes para o desenvolvimento turístico fluminense, deixando claro não ser possível dimensionar o turismo sem as suas devidas bases geográficas. Sendo assim, observa que

\begin{abstract}
a atividade turística não pode ser pensada sem as bases geográficas e, neste contexto, podemos distinguir três condicionantes que influenciam o desenvolvimento da atividade do turismo em território fluminense. Tais condicionantes estão intimamente relacionados. São eles: (a) o elemento físico ou natural; (b) o elemento histórico e as atividades econômicas; e (c) o papel dos transportes (RIBEIRO, 2003, p.81).
\end{abstract}

No estudo organizado por Gomes (2010), derivando da própria apreciação de Ribeiro (2003) quanto à importância da base geográfica, são apontadas áreas turísticas específicas, onde os condicionantes naturais e históricos ganham destaque - a saber: áreas de ecoturismo, de praia e ecoturismo, de praia e rural, de praia, de serra e mar, de serra, serrana da Mantiqueira, Baixada Fluminense, diversificada e o Vale do Café. Já no presente trabalho, com a necessidade de se relacionar motivação e mobilidade nas práticas turísticas com uma porção específica do território fluminense, a Região das Baixadas Litorâneas, identifica-se a Área Turística de Praia como aquela na qual o recorte empírico melhor se dimensiona.

A área em si se notabiliza pelas práticas turísticas dimensionadas pela orla litorânea aprazível, cuja paisagem, raiz da motivação turística, é capaz de atrair quantitativo expressivo de visitantes e onde o produto turístico passa a ser acessível quando a estrutura - e também a superestrutura - turística é mobilizada para tanto (BOULLÓN, 2002). Para o referido autor, a paisagem enquanto elemento da apreciação turística é preestabelecida a partir da relação entre um objeto estético, que é a praia, com o observador sensível, que é o turista. Em sendo assim, define-se a paisagem como

\begin{abstract}
uma qualidade estética que os diferentes de um determinado espaço físico adquirem apenas quando o homem surge como observador animado de uma atitude contemplativa dirigida a captar suas propriedades externas, seu aspecto, seu caráter e outras particularidades que permitem apreciar sua beleza ou feiura (BOULLÓN, 2002, p.120).
\end{abstract}

Definindo, pois, a importância da dimensão da paisagem praiana para a caracterização de uma área turística, parte-se para o apontamento das outras atividades turísticas que podem ser correlacionadas ao turismo de praia. No caso específico do recorte espacial do trabalho, se observa, ainda em acordo com Gomes (2010), a existência de práticas turísticas classificadas como: Turismo Histórico, Turismo de Aventura e Turismo Ecológico.

De fato, a praia incide sobre a ocorrência de outras possibilidades de uso turístico. A orla oceânica, por exemplo, está associada à antiga colonização deste fragmento do território brasileiro, o que no presente possibilita a existência de rugosidades cujo caráter histórico-cultural também mobiliza visitantes em cidades como Cabo Frio, por exemplo. 
Este mesmo mar, associado à praia, explica a ocorrência das práticas de mergulho para exploração submarina, como se verifica junto ao litoral do município de Arraial do Cabo. É a praia, enfim, que possibilita a prática de esportes náuticos, como verificamos de um modo geral nos municípios supracitados, bem como também em Armação dos Búzios.

A Figura $1^{1}$ identifica os municípios envolvidos nesta área turística. São eles: Araruama, Armação dos Búzios, Arraial do Cabo, Cabo Frio, Iguaba Grande, Maricá, Rio das Ostras, São Pedro da Aldeia e Saquarema. Como é destacado no Caderno de Turismo do Estado do Rio de Janeiro, "seu ambiente litorâneo é o principal atrativo turístico, tanto que, a região de governo que envolve esta área é conhecida como Costa do Sol" (GOMES, 2010). Observa-se que no Plano Diretor de Turismo do Estado do Rio de Janeiro, os municípios indicados fazem parte da Região Turística da Costa do Sol, onde estão presentes, para além dos elencados acima, os municípios de Casimiro de Abreu, Macaé, Carapebus e Quissamã - vide a Figura 2).

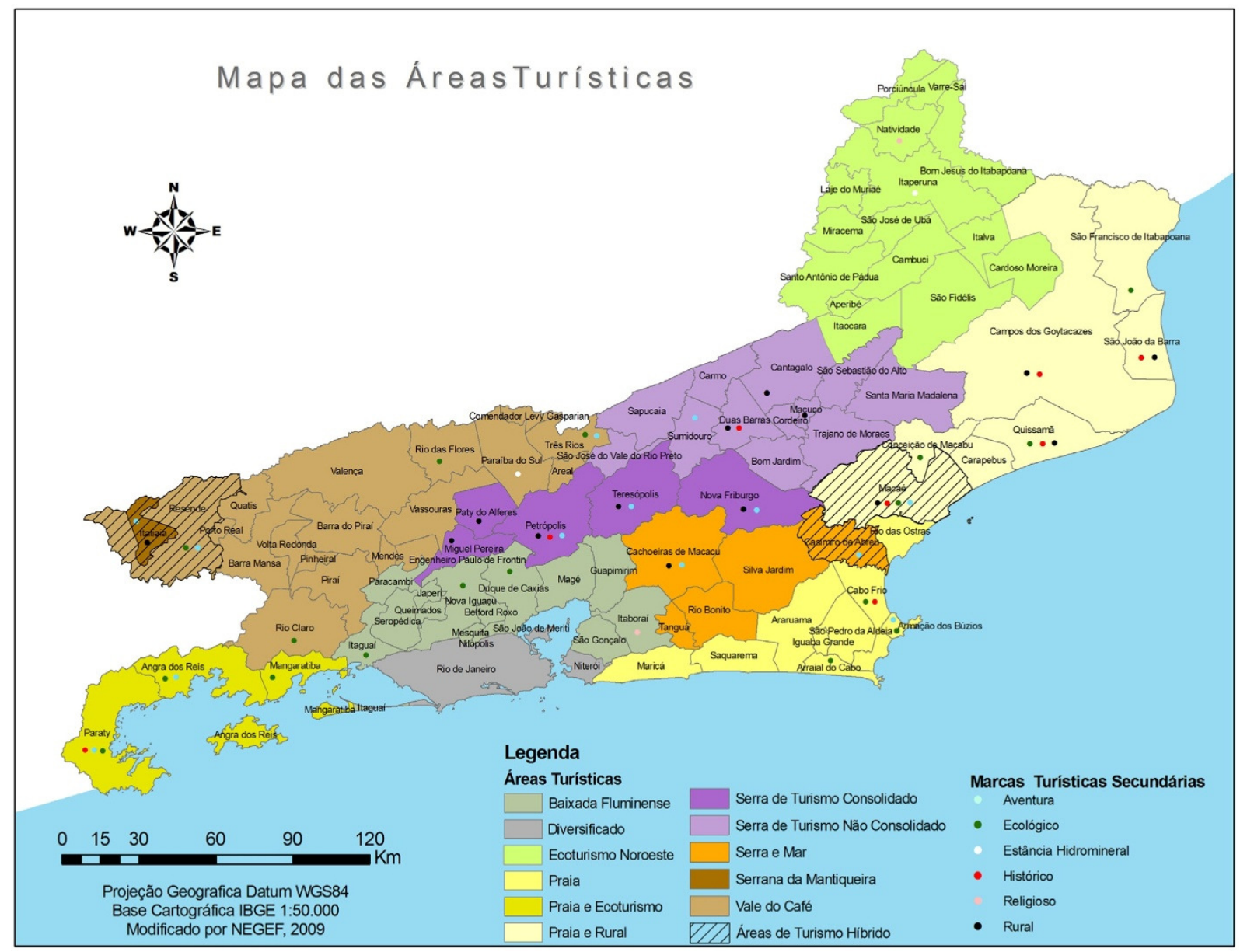

Figura 1: Áreas Turísticas do Estado do Rio de Janeiro. Fonte: Gomes (2010).

Figure 1: Tourist Areas of the State of Rio de Janeiro. Source: Gomes (2010). 


\section{ORGANIZAÇÃO DO TURISMO NO ESTADO}

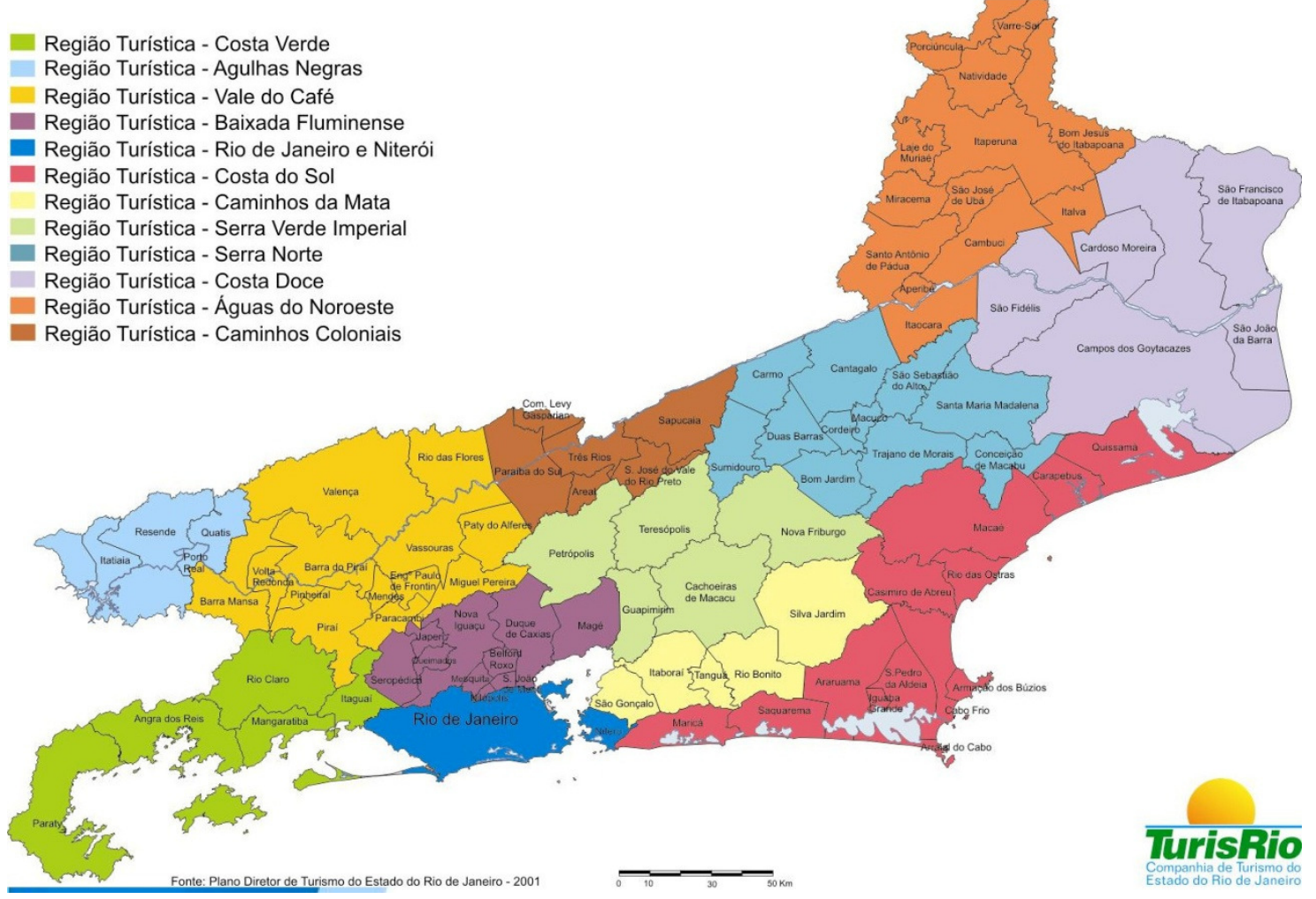

Figura 1: Regiões Turísticas do Estado do Rio de Janeiro. Fonte: Plano Diretor de Turismo do Estado do Rio de Janeiro. TurisRio - Companhia de Turismo do Estado do Rio de Janeiro.

Figure 1: Tourist Regions of the State of Rio de Janeiro. Source: Figura 1: Plano Diretor de Turismo do Estado do Rio de Janeiro. TurisRio - Companhia de Turismo do Estado do Rio de Janeiro.

Conforme a secretaria de Turismo do Estado do Rio de Janeiro, o Plano Diretor de Turismo do Estado do Rio de Janeiro reconhece doze regiões turísticas no Estado, sendo seis delas consideradas estratégicas: Costa Verde, Agulhas $\mathrm{Ne}$ gras, Vale do Café, Rio de Janeiro e Niterói, Serra Verde Imperial e aquela pertinente ao objeto de estudo do presente artigo, a Costa do Sol. Atenta-se para o fato do referido plano indicar a existência de regiões turísticas com características homogêneas, o que difere da proposta organizada por Gomes (2010). Em acordo com o plano diretor,

o mapeamento turístico no Estado resultou na aglutinação de um determinado número de municípios, conferindo praticidade à operação conjunta de ações propostas para o desenvolvimento do setor, sem perder de vista a necessária integração das diversas regiões na realização e promoção do produto turístico de todo o Estado. As regiões turísticas foram identificadas de modo a guardarem, internamente, um sentido de homogeneidade e complementaridade traduzidas pela identidade geográfica, paisagística, territorial e da oferta de infraestrutura e serviços ${ }^{2}$. 
Ora, ao propor um estudo da mobilidade turística na Região da Baixadas Litorâneas, de certo haveria uma premissa, a de destacar o conceito de região. Entretanto, em considerando a análise de uso turístico, como aponta Boullón (2002), este não é o conceito mais adequado. O autor em tela entende que os atrativos turísticos presentes em um determinado espaço são relativamente pouco significativos e, portanto, só excepcionalmente se tocam. Esta condição impediria a conformação de uma região turística em si. Na visão deste autor,

visto que o espaço turístico é entrecortado, não se pode recorrer a técnicas de regionalização para proceder a sua delimitação porque, de acordo com elas, seria preciso abranger toda a superfície do país ou da região em estudo, e caso isso fosse feito, grandes superfícies que não são turísticas figurariam como turísticas, cometendo-se um erro. Isso significa que regiões turísticas não existem (BOULLÓN, 2002, p. 79).

Em assim sendo, a proposta de tratamento da espacialização turística do Estado estaria mais próxima daquela organizada por Gomes (2010) no Caderno de Turismo do Estado do Rio de Janeiro. Este é o entendimento de Boullón (2002), que justifica o desenvolvimento da ideia de espaço turístico. As concentrações de atrativos turísticos no território, pela lógica deste autor, indicaria a existência de múltiplos agrupamentos e concentrações, onde podem ser destacadas as zonas, as áreas, os complexos e os centros turísticos. Esta proposta permite, pois, avançar no sentido de compreender, dentro da chamada Região das Baixadas litorâneas, no Estado do Rio de Janeiro, de uma avaliação do aparato turístico e da atividade turística concentrada em três municípios: Cabo Frio, Arraial do cabo e Armação dos Búzios.

Na verdade, o Plano Diretor de Turismo do Estado do Rio de Janeiro atende a uma necessidade própria do poder público fluminense em considerar uma regionalização da atividade turística. O Estado, conforme disposto por Marafon et alli (2012), enquanto proposta de política pública dimensiona o espaço fluminense em Regiões de Governo. O foco da proposta é a de direcionar as ações públicas voltadas para o desenvolvimento conforme as especificidades geográficas, em sua visão mais abrangente, da cada região fluminense. Seria, portanto plenamente cabível que o agente público promovesse uma leitura regional para o desenvolvimento turístico do Estado.

O entendimento de uma região turística, portanto, embora não desmerecida como um todo deixa de atender aos objetivos da pesquisa em tela. Por um lado, a pertinência da Região das Baixadas Litorâneas como indicativo de uma proposta de política pública de desenvolvimento é determinante para estabelecer o recorte do estudo ora apresentado. Por outro, do ponto de vista teórico-conceitual, não seria pertinente tentar empreender uma leitura da mobilidade turística em uma dada porção do espaço fluminense considerando o conceito de região. Em assim sendo, consideran- 
do sobremaneira as ideias de Boullón (2002), parte-se para a tentativa de compreensão da dinâmica turística presente no recorte espacial elegido pela pesquisa.

\title{
A mobilidade turística na região das baixadas litorâneas (RJ)
}

A mobilidade turística está atrelada à própria significação turística de um dado recorte espacial. O espaço turístico depende, portanto, para além dos próprios atrativos turísticos, do empreendimento turístico em si e da infraestrutura turística disponibilizada. A mobilidade é indicativo daquilo que Boullón chama de área turística, pois envolve a existência de dois ou mais centros turísticos, conforme observa o próprio autor, pois

\begin{abstract}
as áreas turísticas devem estar dotadas de atrativos turísticos contíguos [...] e necessitam, da mesma forma, de uma infraestrutura de transporte e comunicação que possam funcionar como um subsistema, requerem a presença mínima de um centro turístico, e se sua infra-estrutura e recursos de equipamentos e serviços são insuficientes, devem ser registrados como potenciais (BOULLÓN, 2002, p.83).
\end{abstract}

O centro turístico, por seu turno, guarda especificidades dimensionadas pelo quantitativo de atrativos turísticos capazes de motivar o uso turístico de determinado espaço. Ainda considerando ó suprarreferido autor observa-se que o centro turístico "é todo o conglomerado urbano que conta em seu próprio território ou dentro de seu raio de influência com atrativos turísticos de tipo e hierarquia suficientes para motivar uma viagem turística" (BOULLÓN, 2002, p.84).

Neste sentido, dentro da Região de Governo das Baixadas Litorâneas, entre os municípios nela encontrados, apenas três guardam atributos suficientes para serem considerados como centros turísticos: Arraial do Cabo, Cabo Frio e Armação dos Búzios. Para além do entendimento dos atributos indicados por Boullón (2002), esta assertiva é derivada da própria pesquisa empírica realizada. Metodologicamente, houve uma pré-definição dos três municípios para a coleta de dados relativa à mobilidade turística, Obviamente, partiu-se das orientações de Boullón (2002) quanto ao fato de que os centros turísticos necessitariam de certos atributos para assim serem considerados como tal, ou seja, a pré-definição dos municípios elegidos não foi aleatória.

Porém, a coleta de dados passou a mostrar que de fato os três municípios guardavam a condição previamente entendida. Na verdade, o atendimento do objetivo básico da pesquisa envolve demonstrar se há de fato uma mobilidade turística entre os municípios da região de governo indicada. Se os dados coletados não apontam para uma forte mobilidade entre os três municípios destacados, por outro lado, demonstram que os demais municípios da região de governo tem muito pouca interação entre si. Isto por si só já é indicativo da análise feita anteriormente, a de que não se podia tratar o recorte enquanto uma região turística, mas sim como uma área turística. Em parte porque os municípios que se destacam no trato turístico são apenas três e em parte por- 
que o fragmento de espaço e alocação dos objetos turísticos, da infraestrutura de comunicação e dos empreendimentos encontra-se concentrado na franja litorânea da região de governo.

A coleta de dados se deu nos três municípios, sendo aplicados duzentos questionários. Para as demandas específicas desta pesquisa destacam-se os dados relativos aos municípios visitados pelos turistas entrevistados. Elegeram-se atrativos turísticos significativos destes três centros turísticos, a saber: a Praia do Forte em Cabo Frio; a Prainha em Arraial do Cabo; a Praia de Geribá em Armação dos Búzios. Estas praias são as mais conhecidas e frequentadas pelos turistas nos respectivos municípios. A coleta, portanto, objetivava saber se poderia identificar nesses atrativos de maior expoente turistas hospedados de outros municípios da região de governo. Também objetivava saber se os turistas ali presentes se deslocavam para as atrações turísticas de outros municípios da região.

Dos turistas entrevistados em Arraial do cabo, apenas $2 \%$ dos entrevistados não estavam hospedados em um dos três municípios destacados, ou seja, Arraial do Cabo, Cabo Frio e Armação dos Búzios. Significativa também a informação de que cerca de dois terços dos entrevistados ali, em Arraial do Cabo, não estavam hospedados no município. Para além disso, observa-se, conforme a Figura 3, que não há forte mobilidade turística entre os municípios da região de governo que não sejam os três de excelência turística identificada. A mobilidade existe, de fato, mas apenas na área turística que congrega os três centros turísticos.

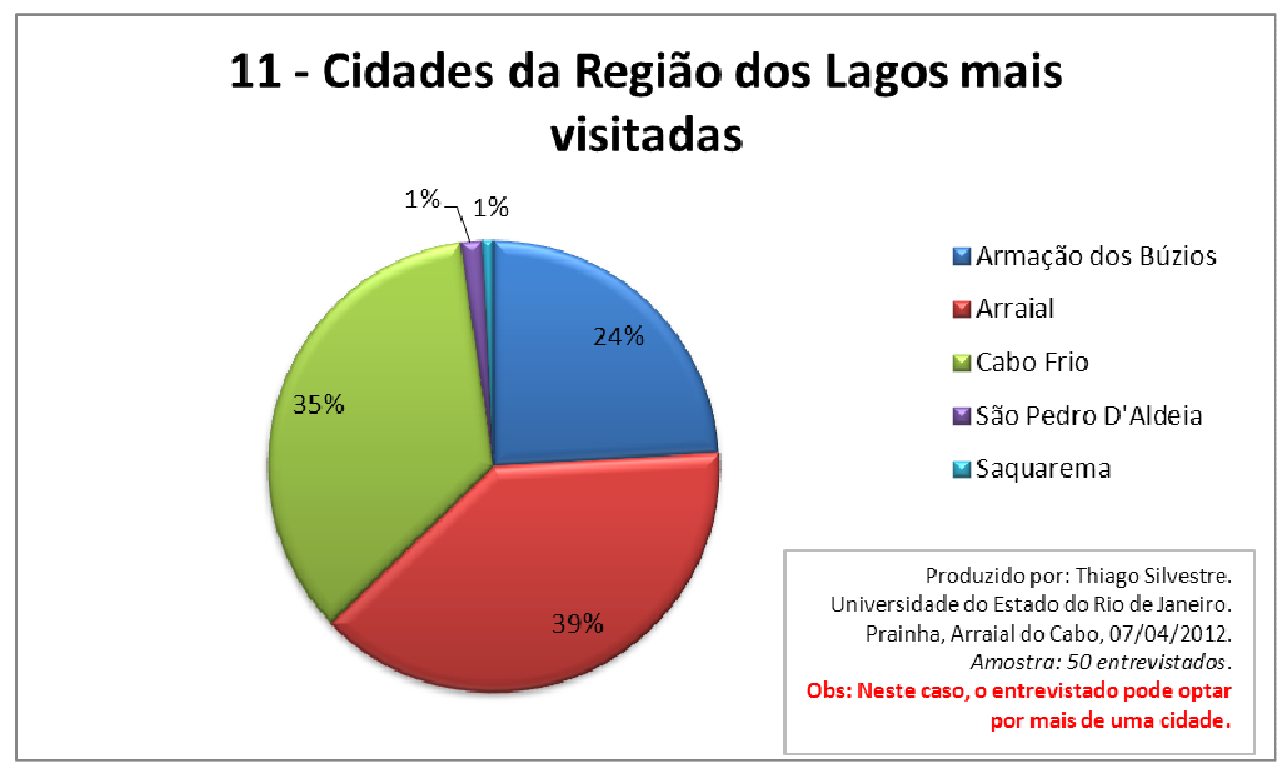

Figura 3: turistas em Arraial do Cabo (RJ). Elaboração: Thiago Silvestre. Figure 3: tourists in Arraial do Cabo (RJ). Preparation: Thiago Silvestre.

Já em Cabo Frio, os entrevistados, em sua grande maioria, estão hospedados na própria cidade. Mais uma vez observou-se que raríssimos eram aqueles não hospedados, para além da localidade analisada, em Armação dos Búzios ou em Arraial do Cabo. Conforme o Figura 4, a mobilidade identificada é pertinente com aquela encontrada em Arraial 
do Cabo, ou seja, os três centros turísticos se completam em termos de mobilidade, mas os demais presentes na região de governo não interagem nesta mobilidade.

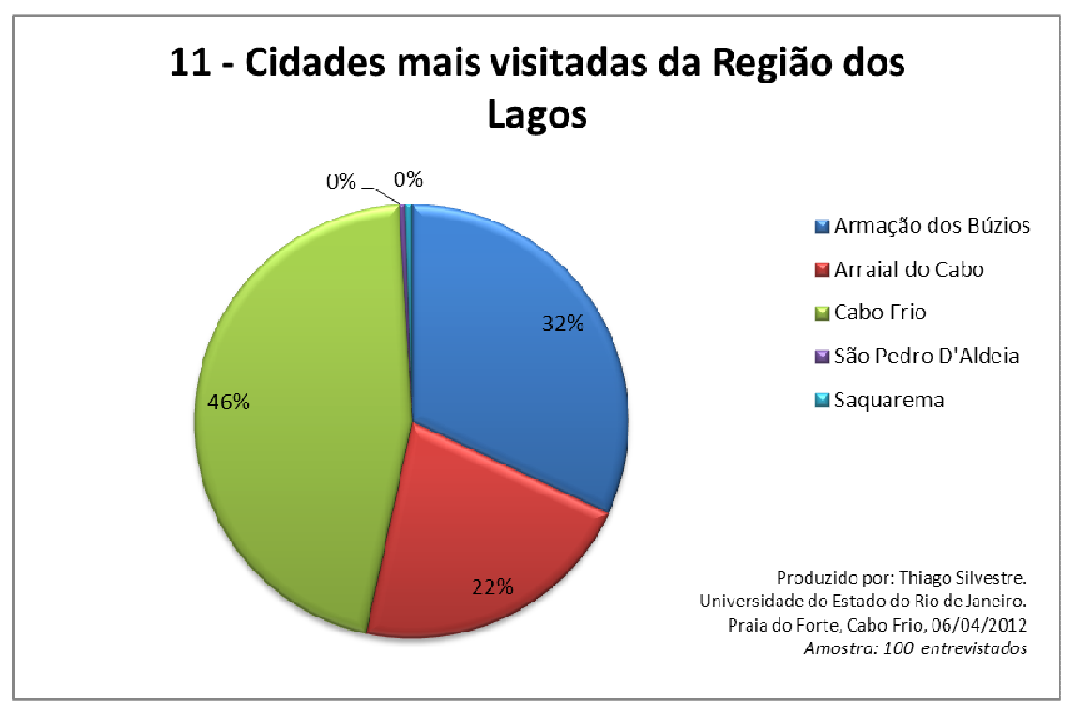

Figura 4: Turistas em Cabo Frio (RJ). Elaboração: Thiago Silvestre.

Figure 4: Tourists in Cabo Frio (RJ). Preparation: Thiago Silvestre.

Em Armação dos Búzios, cerca de três quartos dos entrevistados se encontravam hospedados na própria cidade, número bem mais significativo do que aquele encontrado em Cabo Frio e, mais ainda, em Arraial do Cabo. Entretanto, quando se considera a mobilidade dentro do conjunto de municípios da Região das Baixadas Litorâneas, uma vez destaca-se que a mobilidade interna volta a apresentar um padrão similar ao dos demais municípios analisados, com ocorrência do fenômeno praticamente limitado à trinca de cidades, conforme pode ser observado na Figura 5.

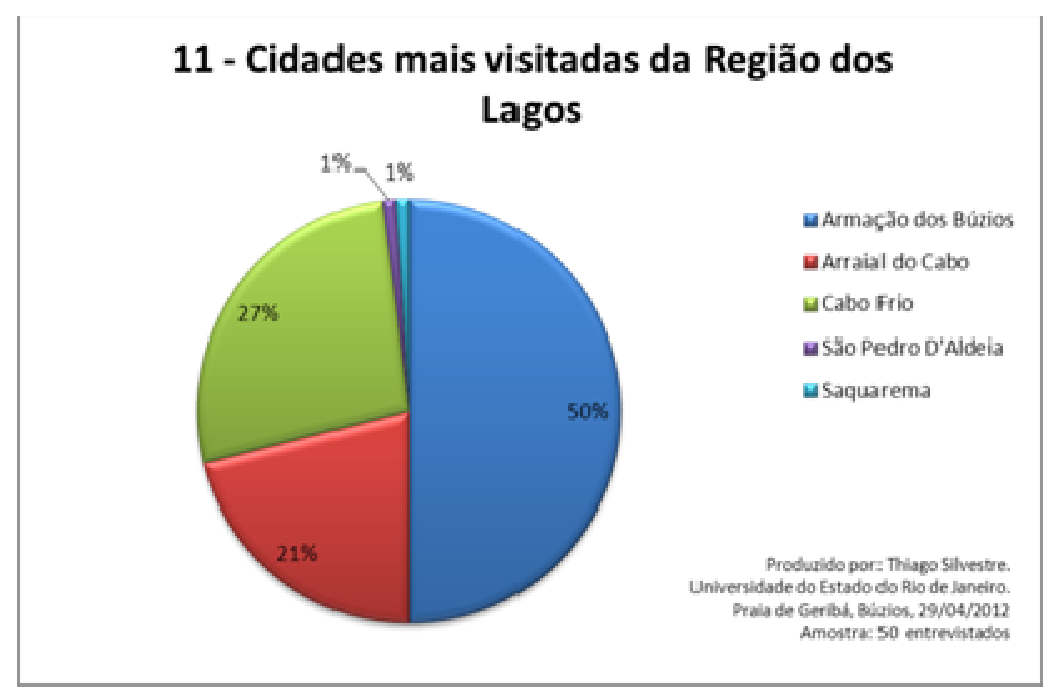

Figura 4: Turistas em Armação de Búzios (RJ). Elaboração: Thiago Silvestre. Figure 4: Tourists in Armação de Búzios (RJ). Preparation: Thiago Silvestre. 
De certo que a motivação turística incide preponderantemente sobre os resultados obtidos. Mas o que leva um determinado turista a considerar suas predileções de uso turístico resulta de um conjunto de considerações que passam pelos atributos naturais e históricos culturais identificados em Ribeiro (2003) e Gomes (2010); que estão guardadas nas análises de Boulón (2002) sobre a paisagem e a estrutura e superestrutura turística; e também na questão da mobilidade proposta por Urry (2000) ou nas motivações turísticas, que são propostas por Shaw \& Williams (2004). Corroborando com esta ideia, considerando todos os turistas entrevistados, raros foram aqueles que não consideraram os municípios de Cabo Frio, Armação dos Búzios e Arraial do Cabo como aqueles onde as atividades turísticas são mais bem desenvolvidas.

\section{Considerações finais}

A análise dos dados e a interação com a base teórica apresentada no estudo organizado por Gomes (2010) e na obra de Boullón (2002) permite elencar duas considerações fundamentais: a área turística analisada não concorre com a Região de Governo das Baixadas Litorâneas, visto ser mínima a mobilidade turística envolvendo os municípios não destacados: Arraial do Cabo, Cabo Frio e Armação dos Búzios; a área turística é de fato concentrada nos municípios em destaque, pois a mobilidade turística está quase que imperceptível para além dos mesmos.

Os atrativos turísticos presentes tanto em Arraial do Cabo quanto em Cabo Frio e Armação dos Búzios dimensionam uma qualificação turística para uma dada porção da Região de Governo das Baixadas Litorâneas. É certo que os dados demonstram laços por demais significativos entre os três centros turísticos, como é certo também indicar uma mínima interação entre os demais municípios da região de governo.

Por outro lado, cabe ressaltar que o avanço da presente pesquisa pressupõe uma coleta de dados nos municípios não contemplados nesta primeira análise. Se a escolha pré-estabelecida dos municípios guarda posicionamento metodológico prévio, também é producente verificar que tipo de mobilidade - e se a mesma existe - entre os demais municípios da região de governo.

Também é correto acreditar que algumas condições pré-existentes e alguns atributos da paisagem natural condicionaram a maior intensificação do uso turístico nesses três municípios analisados. A imaginação analítica permite avaliar que as propostas de ação pública vinculadas aos distintos municípios da região devem pressupor que a maior qualificação das atividades de cunho turístico permitiria maior interrelação entre os distintos municípios da região de governo analisada.

\section{Referências bibliográficas}

BOULLÓN, R.C. Planejamento do Espaço Turístico. Bauru: EDUSC, 2002.

FODNESS, D. Measuring Tourist Motivation. Annals of Tourism Research: A Social Sciences Journal, 1994.

GOMES, J.C. (Org.). Caderno de Turismo do Estado do Rio de Janeiro: Passaporte para o Desenvolvimento do Estado. Rio de Janeiro: Fecomércio, 2010. 
GUIMARÃES, V. Globalização e mobilidade: as condições de mobilidade contemporânea e as práticas turísticas. Revista Contemporânea. 18ª ed. 2011.

HANNAM, K.; SHELLER, M.; URRY, J. Editorial: Mobilities, Immobilities and Moorings. Mobilities. London, v. 1, No. 1, 1-22, March 2006. Disponível em: <http:// dx.doi.org/10.1080/17450100500489189>. Acessado em 24 de maio de 2012.

HARVEY, D. Condição Pós-Moderna. São Paulo: Loyola, 1996.

LASH, S.; URRY, J. Economies of Signs \& Space. London: Sage Publications, 1994. MARAFON, G. et alli. Geografia do Estado do Rio de Janeiro: da Compreensão do Passado aos Desafios do Presente. Rio de Janeiro: Gramma, 2012.

PEARCE, D.G.; BUTLER, R. (Org.). Tourism Research: Critiques and Challenges. Londres: Routledge, 1994.

RIBEIRO, M.A. Turismo no Estado do Rio de Janeiro: Ensaio de Uma Tipologia. GEOgraphia. Niterói, v. 5, n‥ 10, 2003. 79-91 pp.

RODRIGUES, A.B (org). Turismo e Geografia: Reflexões Teóricas e Enfoques Regionais. $2^{\underline{a}}$ ed. São Paulo: Hucitec, 1999.

SHAW, G.; WILLIAMS, A.M.. Tourism and Tourism Spaces. $1^{\underline{a}}$ ed. Londres, Thousand Oaks, Nova Deli: SAGE Publications, 2004.

URRY, J. O Olhar do Turista: Lazer e Viagens nas Sociedades Contemporâneas. São Paulo: Studio Nobel, SESC, 1996.

URRY, J. Sociology Beyond Societies: Mobilities for the Twenty-First Century. $1^{\text {a }}$ ed. Londres: Routledge, 2000.

\section{Notas:}

${ }^{1}$ Este trabalho resulta de pesquisa com o apoio institucional da FAPERJ - Fundação Carlos Chagas de Amparo à Pesquisa - RJ.

${ }^{2}$ O mapa foi elaborado pelo NEGEF - Núcleo de Estudos de Geografia Fluminense, vinculado ao Instituto de Geografia da UERJ. O núcleo participou ativamente da elaboração do estudo organizado por Gomes (2010) - o Caderno de Turismo do Estado do Rio de Janeiro.

${ }^{3}$ Conforme o disposto no sítio eletrônico da SeTur, Secretaria de Turismo do Estado do Rio de Janeiro. Disponível em <http://www.turisrio.ri.gov.br/projetos.asp $>$. Acesso em 30 de maio de 2012.

${ }^{4}$ Neste gráfico, bem como nos seguintes, a pergunta base feita foi: "Quais cidades serão visitadas por você durante a sua estadia na Região dos Lagos?" - o uso do termo Região dos Lagos, de senso comum, foi utilizada para facilitar o entrevistado quanto á apreensão do recorte de estudo. 
Ulisses da Silva Fernandes: Universidade do Estado do Rio de Janeiro, Rio de Janeiro, RJ, Brasil.

Email: usfernandes@bol.com.br

Link para o currículo Lattes: http://lattes.cnpq.br/2728116804299922

Data de submissão: 23 de junho de 2012

Data de recebimento de correções: 08 de abril de 2013

Data do aceite: 08 de abril de 2013

Avaliado anonimamente 